\title{
WALL-FOLLOWING BEHAVIOR-BASED MOBILE ROBOT USING PARTICLE SWARM FUZZY CONTROLLER
}

\author{
Andi Adriansyah' ${ }^{1}$, and Shamsudin H. Mohd. Amin ${ }^{2}$ \\ ${ }^{1}$ Departement of Electrical Engineering, Faculty of Engineering, Universitas Mercu Buana \\ Jl. Meruya Selatan, Jakarta Barat, 11650, Indonesia \\ ${ }^{2}$ Center of Artificial Intelligent and Robotics (CAIRO), Universiti Teknologi Malaysia, \\ Skudai, Johor Bahru, 81310, Malaysia \\ E-mail: andi@mercubuana.ac.id¹, sham@fke.utm.my²
}

\begin{abstract}
Behavior-based control architecture has been broadly recognized due to their compentence in mobile robot development. Fuzzy logic system characteristics are appropriate to address the behavior design problems. Nevertheless, there are problems encountered when setting fuzzy variables manually. Consequently, most of the efforts in the field, produce certain works for the study of fuzzy systems with added learning abilities. This paper presents the improvement of fuzzy behavior-based control architecture using Particle Swarm Optimization (PSO). A wall-following behaviors used on Particle Swarm Fuzzy Controller (PSFC) are developed using the modified PSO with two stages of the PSFC process. Several simulations have been accomplished to analyze the algorithm. The promising performance have proved that the proposed control architecture for mobile robot has better capability to accomplish useful task in real office-like environment.
\end{abstract}

Keywords: behavior-based robot; wall-following behavior; fuzzy logic; PSO; PSFC;

\begin{abstract}
Abstrak
Arsitektur pengendali robot berbasis perilaku telah secara efektif menunjukkan kompetensinya dalam pengembangan teknologi robot bergerak. Karakteristik sistem logika fuzzy adalah salah satu solusi yang dapat diandalkan untuk menyelesaikan beberapa problem pada perancangan perilaku robot. Akan tetapi, terdapat kesulitan untuk dapat menala parameter fuzzy secara manual. Oleh karena itu beberapa studi dilakukan untuk mengintroduksi kemampauan pembelajaran pada sistem logika fuzzy. Tulisan ini membahas pengembangan arsitektur pengendali robot berbasis perilaku dengan memanfaatkan Particle Swarm Optimization (PSO). Perilaku robot mengikuti dinding berbasiskan Particle Swarm Fuzzy Controller (PSFC) dibangun menggunakan PSO yang telah dimodifikasi dengan dua tahap proses PSFC. Beberapa pengujian telah dilakukan untuk menganalisa performansi algoritma tersebut. Hasil pengujian menunjukkan bahwa perancangan tersebut memiliki performansi yang menjanjikan bahwa robot dapat menyelesaikan tugasnya dengan baik pada suatu lingkungan tertentu.
\end{abstract}

Kata Kunci: robot berbasis perilaku; perilaku pengikut dinding; logika fuzzy; PSO; PSFC;

\section{Introduction}

Emerging a mobile robot is a remarkable task. Usually, the mobile robot should face unpredictable environment, perceive inaccurate sensor and act with unsatisfactory actuator in high speed response $[1,2]$. Behavior-based control architecture is an alternative method suitable to address these problems [3-7]. The architecture is able to act with fast real-time response, provides for higher level deliberation and has confirmed its reliable results in standard robotic activities. However, a kind of so$\mathrm{ft}$ computing is needed to complete two key problems in behavior-based systems, such as genera- ting optimal individual behavior and coordinating multiple behaviors.

Currently, several methods that hybrid fuzzy system with evolutionary algorithms has been offered in behavior-based mobile robot, such as Genetic Algorithm (GA) [8,9], Genetic Programming [10] to overcome the behavior-based issues. However, the current evolutionary algorithms used have several drawbacks [11], such as not easy to be implemented and computationally expensive [12], require process should be completed and parameters should be adjusted, have slow convergence ability to find near optimum solution, and dependent heuristically to genetic operators [13]. 
Fortunately, Kennedy and Eberhart presented the Particle Swarm Optimization in 1995 [14, 15]. PSO is one of evolutionary computation technique to find the best solution by acting like social behavior of groups such as fish schooling or bird flocking. There are several benefits of the PSO as compared to other evolutionary computation methods. The PSO is not difficult to be implemented and is computationally reasonable since its memory and CPU speed requirements are low. Additionally, the PSO requires only a few process should be completed and parameters to be adjusted. On the other side, the PSO has quick convergence ab-ility to find optimum or near optimum solution. Generally, PSO has demonstrated to be an effecttive method for numerous wide ranging optimization problems. Moreover, in some cases it does not suffer from the problems encountered by other evolutionary computation [11-13].

This paper addressed the problems of developing control architecture of mobile robot with behavior-based system, especially in wall-following. The problem solving is related to the specification of mobile robot tasks, the development of mobile robot behaviors, the interpretation of the environment, and the validation of the final system. This paper uses and develops soft computing, making extensive use of Fuzzy Logic and Particle Swarm Optimization (PSO) named as Particle Swarm Fuzzy Controller (PSFC). The use of PSO is to tune fuzzy membership function and to learn fuzzy rule base for wall-seeking behavior. This fuzzy tuning and learning is performed to accomplish the best behavior-based system.

\section{Methods}

Wall-following behavior steer the robot to follow wall in order to help goal accomplishment. Based on some distances measured between the mobile robot and the walls, the mobile robot would maintain some fixed distance between both robot and the wall even at edges [16-18]. In this work, MagellanPro mobile robot is used for verification and performance analysis of the proposed algorithm. The MagellanPro is a rounded mobile robot from iRobot, Real World Interface (RWI), the recognized industry leader in the exciting field of pioneering mobile robotic. The dimension of the robot is as follow: $\mathrm{D}=40.64 \mathrm{~cm}, \mathrm{H}=25.4 \mathrm{~cm}, \mathrm{r}=5.7 \mathrm{~cm}, \mathrm{~W}=$ $36 \mathrm{~cm}$ and $M=18.2 \mathrm{~kg}$, where $\mathrm{D}$ is diameter, $\mathrm{H}$ is height, $\mathrm{r}$ is the radius of wheels, $\mathrm{W}$ is distance between two wheels, and $\mathrm{M}$ is mass.

Figure 1 illustrated a model of MagellanPro mobile robot for simulation exercises for the proposed algorithm. The mobile robot is positioned on a two dimensional Cartesian workplace, in wh-ich a global coordinate $\{X, O, Y\}$ is defined. The robot

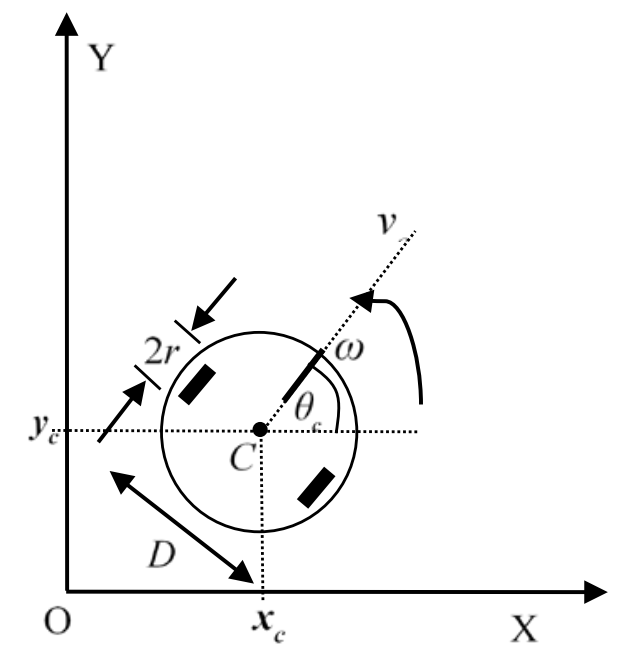

Figure 1. Model of MagellanPro mobile robot

has three degrees of position that are represented by a posture $p_{c}=\left(x_{c}, y_{c}, \theta_{c}\right)$, where $\left(x_{c}, y_{c}\right)$ indicate the spatial position of the robot guide point in the coordinate system and $\theta_{c}$ is the heading angle of the robot counter-clockwise from the $\mathrm{x}$-axis.

The mathematical model for the robot movement can be obtained with differentially steered drive system or known as differential drive system [19]. Based on this system, the robot can move to different positions and orientations as a function of time. The derivatives of $x, y$ and $\theta$ can be obtained as equation(1) to equation(3).

$$
\begin{gathered}
\frac{d x}{d t}=v_{c} \cos \theta_{c} \\
\frac{d y}{d t}=v_{c} \sin \theta_{c} \\
\frac{d \theta}{d t}=\omega_{c}
\end{gathered}
$$

where $\omega_{c}$ is the angular velocity of the robot and where $v_{c}$ is the linear velocity of the robot.

By applying the current position of the robot, $p_{c}=\left(x_{c}, y_{c}, \theta_{c}\right)$, the next position of the mobile robot is shown in equation(4) to equation(6).

$$
\begin{gathered}
x_{c+1}=x_{c}+v_{c} \cos \theta_{c} * \Delta t \\
y_{c+1}=y_{c}+v_{c} \sin \theta_{c} * \Delta t \\
\theta_{c+1}=\theta_{c}+\omega_{c} * \Delta t
\end{gathered}
$$

Then, as assuming the value of $\Delta t$ is a unit time step, the next position of the robot which also can be written as $p_{c+1}=\left(x_{c+1}, y_{c+1}, \theta_{c+1}\right)$, in a simple form is given by the equation(7) to equation(9). 


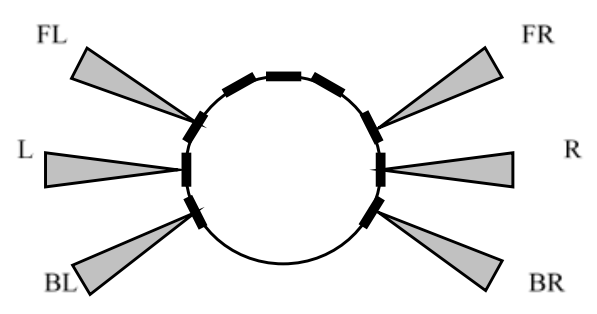

Figure 2. Sonar Configuration

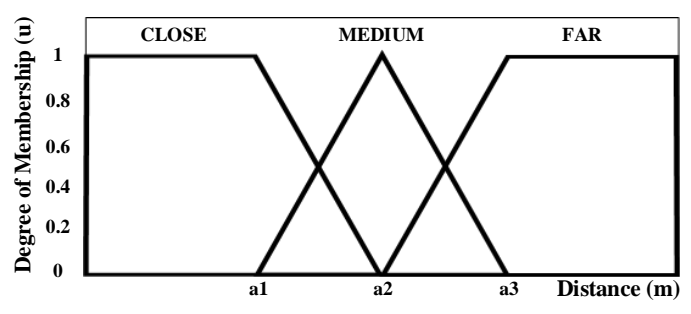

Figure 3. The membership functions of distances and angle

$$
\begin{gathered}
x_{c+1}=x_{c}+v_{c} \cos \theta_{c} \\
y_{c+1}=y_{c}+v_{c} \sin \theta_{c} \\
\theta_{c+1}=\theta_{c}+\omega_{c}
\end{gathered}
$$

In order to make the robot able to follow the wall then six sonar have been mounted on them. These sensors would measure the distance between positions of sonar in mobile robot and the object accordingly. The positions of sonars are illustrated in Figure 2.

There are two zones of sensor, namely: Left Zone Sensors and Right Zone Sensors. Left Zone Sensors comprise Back Left (BL), Left (L), and Front Left (FL). Meanwhile, Right Zone Sensors consist of Front Right (FR), Right (R) and Back Right (BR). The angle between sonars is 22.5 degree. Each zone of sonar's is according to a behavior. The behavior constitutes: Left Zone Sensors with left wall following behavior and Right Zone Sensors with right wall following behavior. Distances obtained by sonar's process in each zone are used as the input on behalf of a behavior.

FLC structure based on Mamdani technique is used in this system. Each left wall following behavior and right following behavior have three inputs. The inputs are front left distance (FL), left distance (L) and back left distance (BL) used for left wall following behavior, and front right distance (FR), right distance (R) and back right dist-
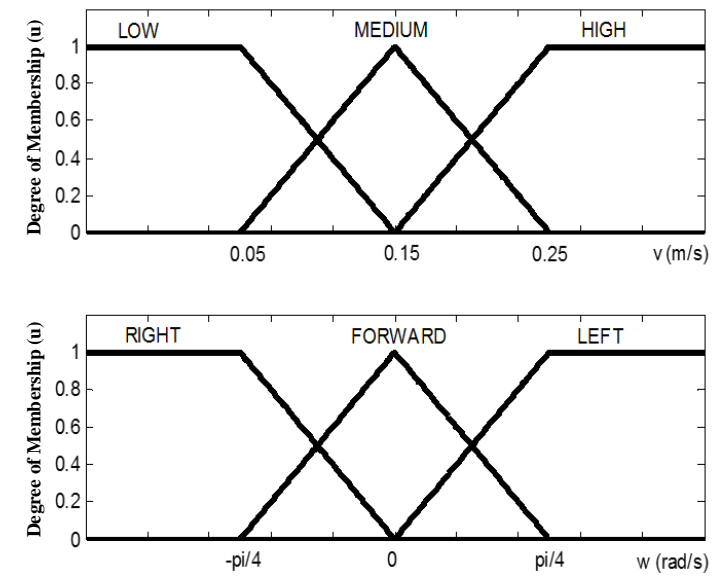

Figure 4. The membership function of linear velocity and angular velocity

ance (BR) used for right wall following behavior. All the distances are obtained by sonar sensor.

The fuzzy input has three linguistic terms, which are CLOSE, MEDIUM and FAR for distances and RIGHT, FORWARD and LEFT for angle, as depicted generally in Figure 3. Three linguistic terms is chosen on behalf of the minimal number for fuzzy system.

In this work, linear velocity $v$ and angular velocity $\omega$ are applied as outputs of all fuzzy behavior modules. The linguistic terms used are LOW, MEDIUM and HIGH for linear velocity, and, RIGHT, FORWARD, and LEFT for angular velocity. The fixed membership functions of $v$ and $\omega$ is shown in Figure 4.

Basically, Particle Swarm Fuzzy Controller is an FLC improved by a tuning or learning process based on PSO. In PSFC, PSO is applied to explore for an optimized Knowledge Base (KB) of a fuzzy system for a specific problem and to ensure those parameter values are suitable with respect to the design principles. The KB parameters establish the optimization space, which is then transformed into suitable position on which the explore process operates. Figure 5 shows the concept of a PSFC scheme where PSO design and fuzzy processing are the two fundamental parts.

At the beginning of the process, the initial populations comprise a set of particles that are scattered all over the search space. The initial population may be randomly generated or may be partly supplied by the user. However, in this works, the populations are randomized initially.

Afterward, one particle is taken and decoded to the actual value of the wall-following fuzzy parameter. These sets of fuzzy controller parameters are then used to control the fuzzy behavior where it undergoes a series of tracking response of multistep reference set point. 


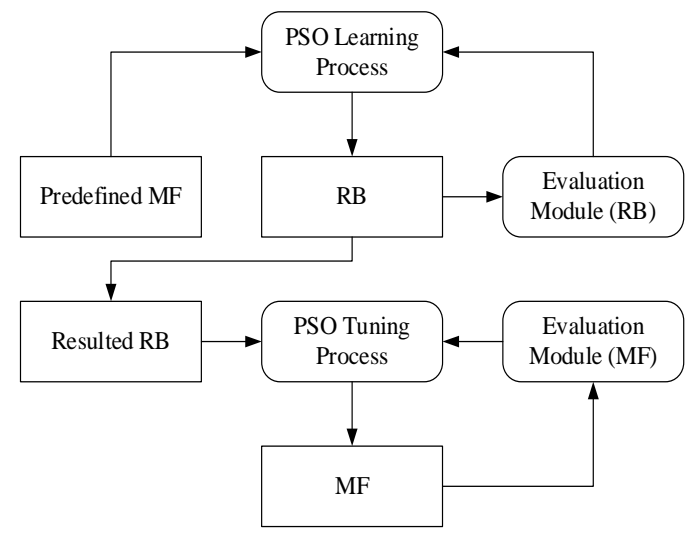

Figure 5. The concept of a PSFC

Based on the various state of the control system, the performance of the system is calculated by using a predefined fitness function.

In the first stage, PSO starts to learn fuzzy rule base with predefined fuzzy membership function. In the next stage, PSO continues to tune fuzzy membership functions based on the results from the fuzzy rule base. By means of these two stages, ideal fuzzy parameter could be reached without human intervention. PSO is then used to tune the fuzzy controller parameters to minimize the fitness function. The assignment of the fitness function serves as a guidance to lead the search toward the optimal solution.

In the beginning, to learn fuzzy rule base, each rule is prearranged into integer codes that are created on number in linguistic terms of output membership function. Consequently, there are ' 1 ', '2', and ' 3 ' for LOW, MEDIUM, and HIGH for linear velocity, and RIGHT, FORWARD, and LEFT for angular velocity, respectively. The coded parameters for each behavior are arranged to form particles of the population.

Furthermore, fuzzy membership functions are tuning with equation(10) and equation(11).

$$
\begin{aligned}
& C_{X+1}=C_{X}+k_{i} \\
& D_{X+1}=D_{X}+j_{i}
\end{aligned}
$$

where $k_{i}$ and $j_{i}$ are adjustment coefficients, $C_{x}$, and $D_{x}$ are set of center and width of each fuzzy membership function, respectively. The adjustment coefficients take any real positive or negative value. Therefore, $k_{i}$ makes each center of membership function shift to the right or left and the membership functions shrinks or expands through $j_{i}$, as shown in Figure 6. The shifting coding strategy will simplify searching computation, because there is no necessity to sort the value of membership functions in ascending manner.

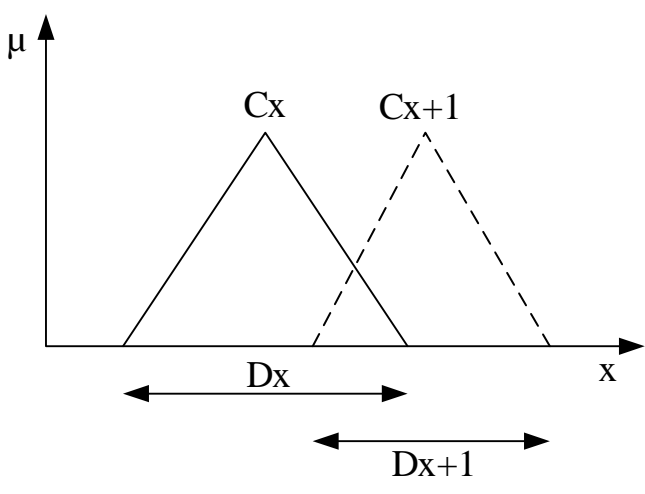

Figure 6. Principle in tuning of membership function

The PSO procedure starts with randomly prearranged initial populations. Then, all populations of particles are assessed based on fitness function to decide the pbest and gbest. Based on several initial investigations and trials and errors, the fitness functions for wall-following can be obtained as equation(12).

$$
f_{\text {wall }}=\sum_{i=0}^{I} \sum_{k=0}^{K}\left(100 e_{d}^{2}(k)+0.1 / v(k)\right)
$$

where $I$ is the entire number of start position, $K$ is the number of step simulation for each start position, $e_{d}$ is the distance error and $v(k)$ are the linear velocity at $k$, respectively.

In this work, a Sigmoid Decreasing Inertia Weight (SDIW) is used to provide faster speed of convergence and better accuracy of optimized value [20]. Consequently, PSFC would generate optimal and reliable wall-following behavior of the mobile robot.

\section{Results and Analysis}

Some experiments have been performed. Some steps of experiments have been designed. Firstly, a PSFC optimization processes is conducted to find the optimized value of fuzzy parameters. Then, simulations of the mobile robot based on the PSFC are analyzed to investigate the wall-following control behavior. Results of fuzzy behavior that are obtained manually, obtained by GA, called as Genetic Fuzzy Controller (GFC) from previous works are used as comparison [21].

PSO and GA processes for wall-following behavior are shown in Figure 7, where, evolutions of the best fitness value against generation are illustrated. At the beginning, the process tended to have more global search ability because of large inertia weight. It was shown that the fitness value over all generations is converging quickly. After that, the process tended to have more local search ability 


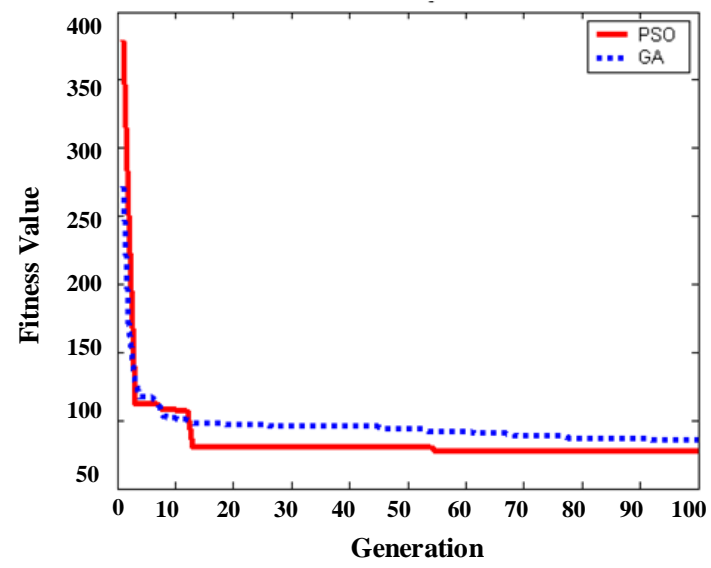

(a)

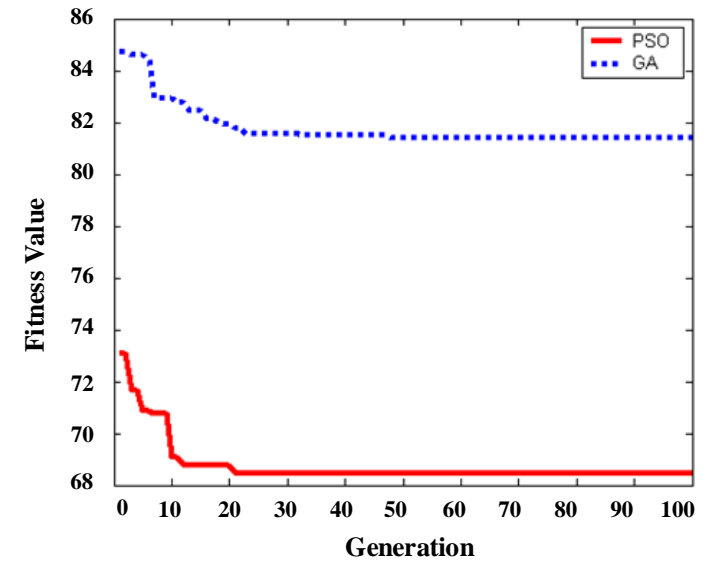

(b)

Figure 7. Comparison of PSO vs. GA process (a) Rule base learning, (b) Membership function tuning
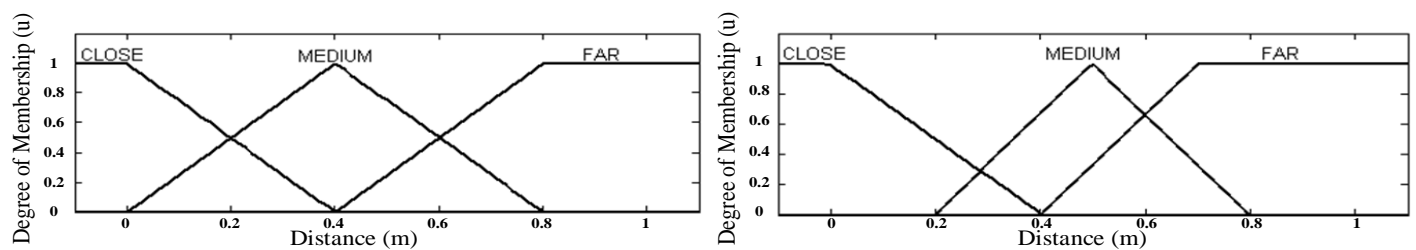

Figure 8. Membership function of left wall following behavior before and after optimization

TABLE 1

COMPARISON OF FITNESS VALUES

\begin{tabular}{lc}
\multicolumn{1}{c}{ Process } & Fitness Value \\
\hline FLC (manually) & 254.1924 \\
GA (Stage 1) & 84.9731 \\
GA (Stage 2) & 81.4125 \\
PSO (Stage 1) & 76.705 \\
PSO (Stage 2) & 68.4668 \\
\hline
\end{tabular}

caused by the small value of inertial weight. This phenomenon was illustrated by the value of fitness function updated towards the lowest one. Moreover, the figures showed that the kind of searching in RB learning process is wider than in MF tuning process. It showed that learning the rule base of FLC is very complicated than tuning the membership. It was also evidenced that the best optimized fitness value could be obtained using two stages of PSO process.

Furthermore, a comparison between Particle Swarm Optimization and Genetic Algorithm was investigated. Table I listed the fitness value based on the process to show a comparison between learning or tuning fuzzy parameters manually, GA process and PSO process. It is noted that PSO and GA provided better results than FLC, but PSO had higher convergence speed and obtained better optimized value than GA. Figure 8 depicted membership function change for wall-following behavior generated by PSO process.

The target of left wall following or right wall following behavior is that the mobile robot could maintain the distance between the robot and the wall while detecting the wall in its left side or right side, respectively. Left wall following is use-d here for experiments showed. As described bef-ore, the wall was represented as a sequence of poi-nts and assumed as a thin wall. In this work, the maintained distance is $0.4 \mathrm{~m}$. Hence, a left edge wall was planed and placed with $3 \mathrm{~m}$ long vertically and $2 \mathrm{~m}$ long horizontally in a room. The mobile robot movements from different starting position were demonstrated and the time responses, which are left distance, linear velocity and angular velocity, were presented.

Figure 9 demonstrated the mobile robot movements from position $(6.4,2.5, \pi / 2)$, the initial distance from the wall is $0.2 \mathrm{~m}$ and with $\mathrm{t}=20 \mathrm{~s}$. As previous experiments, the fuzzy behavior was obtained using FLC, GFC and PSFC. Furthermore Figure 11 (a) presented time response for each algorithm, accordingly. Figure 10 and Figure 11 (b) demonstrated that the three algorithms provided different control performance. Fuzzy behavior obtained by FLC had the worst performance. The response time to maintain the distance was very slow. Furthermore, the algorithm was also very sensitive to disturbance. It was shown that angular velocities fluctuated and the linear velocity reduced when the mobile robot runs in the left edge situation. However, the fuzzy behavior obtained by PSFC had better performance as compared to GFC. For both al- 


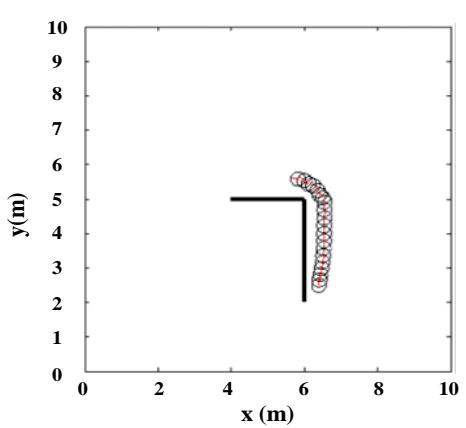

(a)

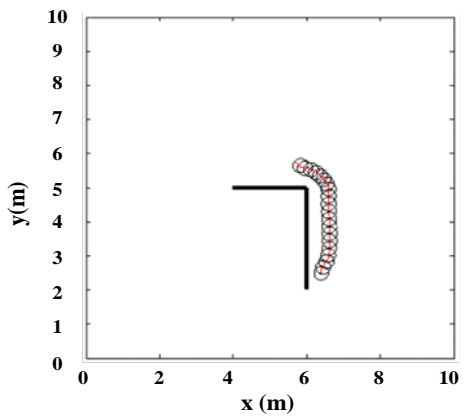

(b)

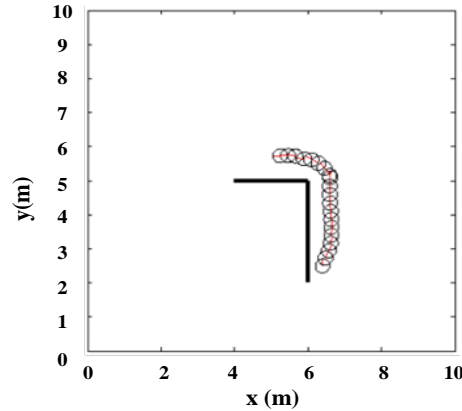

(c)

Figure 9. Mobile Robot movements for left wall following behavior starting from $(6.4,2.5, \pi / 2)$ (a) FLC, (b) GFC, and (c) PSFC

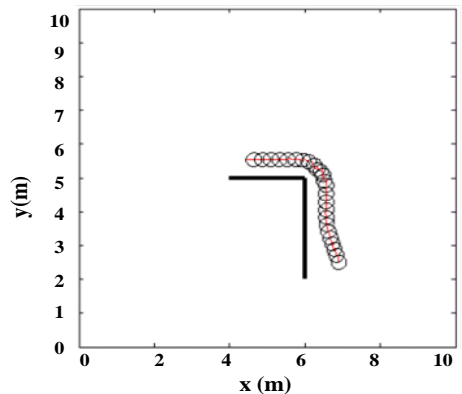

(a)

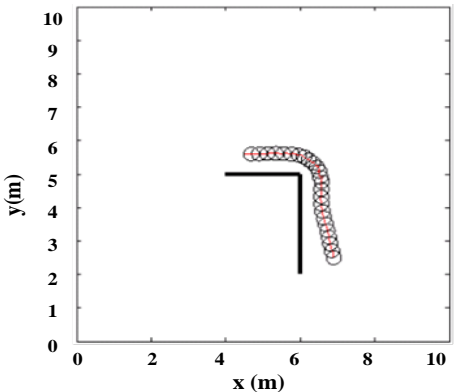

(b)

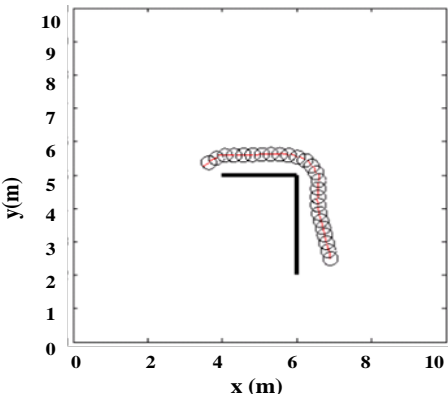

(c)

Figure 10. Mobile Robot movements for left wall following behavior starting from $(6.9,2.5, \pi / 2)$ (a) FLC, (b) GFC, and (c) PSFC
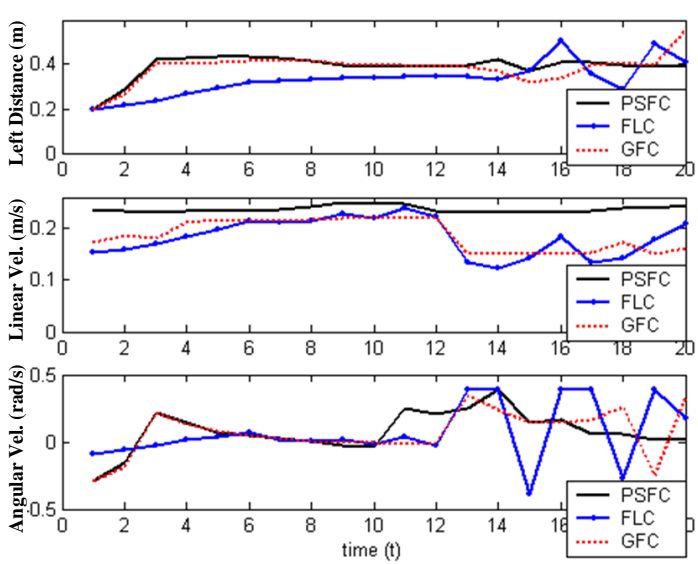

(a)
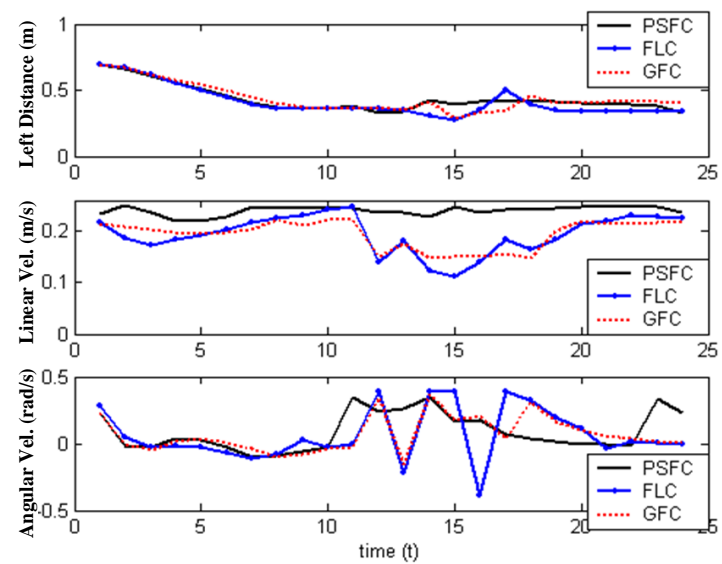

(b)

Figure 11. Time response of left wall following using FLC, GFC, and PSFC, starting from (a) $(6.4,2.5, \pi / 2)$ and (b) $(6.9,2.5, \pi / 2)$

gorithms in spite of providing the same response of distance, the PSFC was less sensitive to disturbance than the GFC when the mobile robot runs in the left edge situation. It is noted that the PSFC can perform the left edge situation with higher linear velocity and with relatively less change in angular velocity.

Different starting positions and different wall structure were presented to further investigate the performance of the left wall following fuzzy behaviors. Figure 10 showed the mobile robot movements from position $(6.9,2.5, \pi / 2)$, the initial distance from the wall is $0.7 \mathrm{~m}$ and $\mathrm{t}=25 \mathrm{~s}$ with the same shape of wall. The time response for each algorithm, accordingly, was shown in Figure 11 (b). Moreover, the mobile robot movements form position $(6.4,2.5, \pi / 2)$, the initial distance from the wall is $0.2 \mathrm{~m}$ and $\mathrm{t}=25 \mathrm{~s}$ with unstructured wall was depicted in Figure 12. Figure 13 showed the time response for each algorithm, accordingly. From Figures 12 and 13, it is noted that PSFC had better performance than other fuzzy behaviors, which are FLC and GFC. The fuzzy behavior obtained by PSFC had the fastest response time, able to main- 


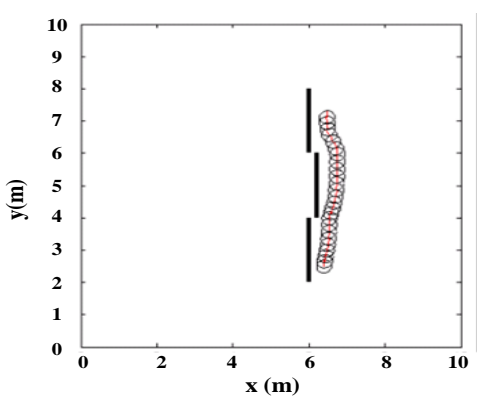

(a)

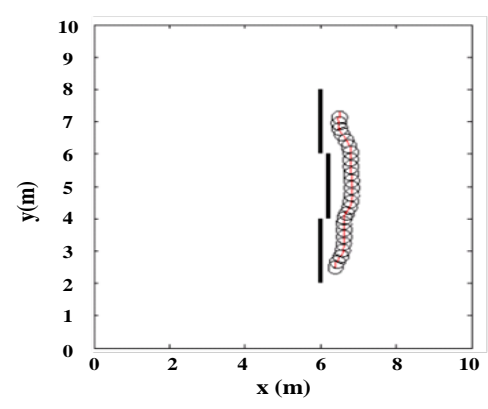

(b)

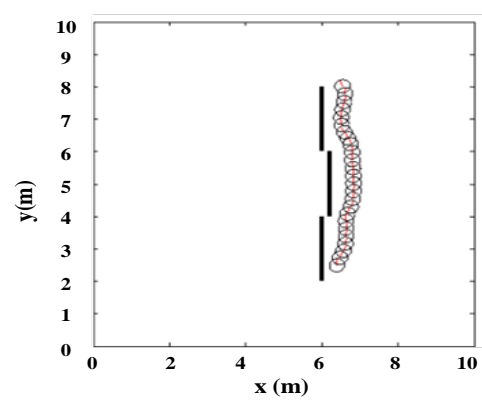

(c)

Figure 12. Mobile Robot movements for left wall following behavior with unstructured wall starting from $(6.4,2.5, \pi / 2)(a)$ FLC, (b) GFC, and (c) PSFC
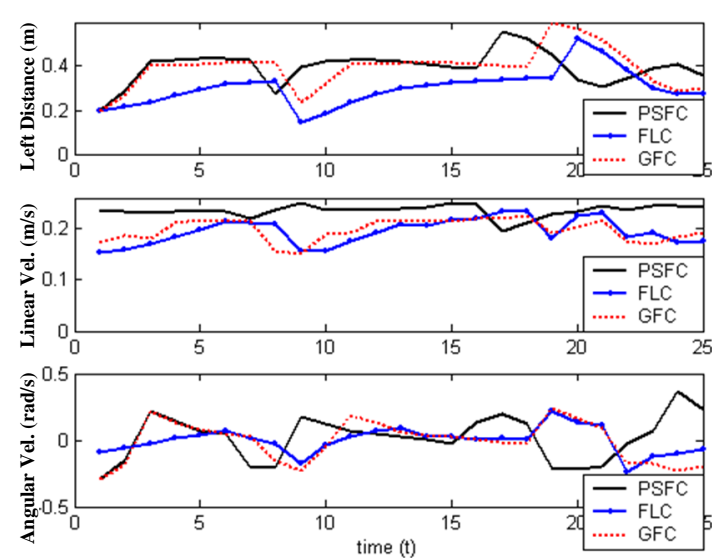

Figure 13. Time response of left wall following with unstructured wall starting from $(6.4,2.5, \pi / 2)$ using FLC, GFC, and PSFC

tain the distance successfully with higher speed and less changed in the direction of the mobile robot, especially when the robot faced unstructured wall.

\section{Conclusion}

Wall-following behavior-based control architectture has successfully demonstrated their competence in mobile robot development. Fuzzy Logic Systems appear to be very useful to develop the high reliable and effective behavior-based system. However, there are difficulties to tune Fuzzy Sys-tem manually. This paper presents the development of fuzzy wall-following behavior-based control architecture using PSO for MagellanPro mobile robot. The work has been done in some tasks: behavioral designing of the mobile robot.

Based on the experiment results, the mobile robot is able to deal with wall-following behaviors. Generally, it is noted that the proposed control architecture has the good ability to be applied in MagellanPro mobile.

\section{Acknowledgement}

The author wishes to express his sincere recognitions to the Directorate General of Higher Education, Ministry of Research, Technology and Higher Education which awarded the grant funding for Fundamental Research (Project No. 2013 0263/E5/ 2014).

\section{References}

[1] Widodo, N. S, Rahman, “A. Vision Based Self Localization for Humanoid Robot Soccer”, TELKOMNIKA, Vol. 10(4), pp. 637644, 2010.

[2] Wicaksono, H, Khoswanto, H., and Kuswadi, S. "Teleautonomous Control on Rescue Robot Prototype”, TELKOMNIKA, Vol.10 (4), pp. 621-628, 2012.

[3] Dongshu, W., Yusheng, Z., and Wenjie, S. "Behavior-Based Hierarchical Fuzzy Control for Mobile Robot Navigation in Dynamic Environment”, Chinese Control and Decission Control (CCDC 2011), China, pp. 24192424, 2011.

[4] Parasuraman, S., Ganapathy, V., and Shirinzadeh, B. "Behaviour Based Mobile Robot Navigation Technique AI System: Experimental Investigation on Active Media Pio-neer Robot”, IIUM Engineering Journal, Vol. 6 (2), pp. 13-25, 2005.

[5] Bao, Q.Y., Li, S.M., Shang, W.Y., and An, M.J. “A Fuzzy Behavior-based Architecture for Mobile Robot Navigation in Unknown Environments", International Conference on Artificial Intelligence and Computational Intelligence (AICI 2009), Shanghai, pp. 257261, 2009.

[6] Mo, H., Tang, Q., and Meng, L. "Behaviorbased Fuzzy Control for Mobile Robot Navigation”, Mathematical Problems in Engineering, pp. 1-10, 2010. 
[7] Khatoon, S, Ibraheem. “Autonomous Mobiler Robot Navigation by Combining Local and Global Techniques”, International Journal of Computer Applications. Vol. 37(3), pp. 1-10, 2012.

[8] Sim, K. B., Byun, K.S., and Lee, D. W. "Design of Fuzzy Controller using Schema Coevolutionary Algorithm”. IEEE Transaction of Fuzzy System, Vol. 12(4), pp. 565-570, 2004.

[9] Merchan-Cruz, E. A., Moris, A. S. "FuzzyGA-based trajectory planner for robot manipulators sharing a common workspace", IEEE Transaction On Robotics, Vol. 22(4), pp. 613-624, 2006.

[10] Tunstel, E.W, de Oliveira, M.A.A., and Berman, S. "Fuzzy Behavior Hierarchies for Multi Robot Control”. International Journal of Intelligent Systems. Special Issue: Hierarchical Fuzzy Systems. Vol. 17(5), pp. 449470, 2002.

[11] Saxena, A. and Saxena, A. "Review of Soft Computing Techniques used in Robotics Application”, International Journal of Information and Computation Technology. Vol. 3(3), pp. 101-106, 2013.

[12] Hassan, R., Cohanim, B, and de Weck, O. “A Comparison of Particle Swarm Optimization and the Genetic Algorithm”, American Institute of Aeronautics and Astronautics, pp. 113, 2004.

[13] Jones, K.O. “Comparison of Genetic Algorithm and Particle Swarm Optimization”, Proceeding of International Conference on Computer Systems and Technologies. Bulgaria. Vol. IIIA, pp. 1-6, 2005.

[14] Eberhart, R.C. and Kennedy, J. “A new optimizer using particle swarm theory”, Proceeding of the Sixth International Symposium on Micro Machine and Human Science. Nagoya, pp. 39-43, 1995.

[15] Kennedy, J. and Eberhart, R.C. "Particle Swarm Optimization”, Proceeding of IEEE International Conference on Neural Networks. IV. Perth, pp. 1942-1948, 1995.

[16] Hsiao, C. W., Chien, Y. H., Wang,W. Y., "Wall Following and Continously Stair Climbing Systems for A Tracke Robot”, International Conference on Networking, Sensing and Control, pp. 371-375, 2015.

[17] Dash, T., Nyak, T. and Swin, R., "Controlling Wall Following Robot Navigation Based on Gravitational Search and Feed Forward”, Proceeding of the $2^{\text {nd }}$ International Conference on Perception and Machine Intelligence, pp. 196-200, 2015.

[18] Juang, C. F. Chen, Y. H. and Jhan, Y. H., "Wall-following Control of Hexapod Robot using a Data-Driven Fuzzy Conroller Learned through Differentiial Evolution”, IEEE Transactions on Industrial Electronics, Vol. 62 (1), pp. 611-619, 2015.

[19] Dudek, G. and Jenkin, M. Computational Principles of Mobile Robotics. $1^{\text {st }}$ ed. Cambridge, MA: Cambridge University Press. 2000.

[20] Adriansyah, A., Amin, S HM. “Analytical and Empirical Study of Particle Swarm Optimization with A Sigmoid Decreasing Inertia Weight”, Regional Postgraduate Conference on Engineering and Science. Johor Bahru, pp. 247-252, 2006.

[21] Adriansyah, A. and Amin, S.H.M. "Knowledge Base Tuning using Genetic Algorithm for Fuzzy Behavior-based Autonomous Mobile Robot”, Proceeding of $9^{\text {th }}$ International Conference on Mechatronics Technology. Kuala Lumpur, pp. 20-125, 2005. 